\title{
Climate change adaptation cost and residual damage to global crop production
}

\author{
Toshichika Iizumi ${ }^{1, *}$, Zhihong Shen ${ }^{1}$, Jun Furuya ${ }^{2}$, Tatsuji Koizumi ${ }^{3}$, \\ Gen Furuhashi ${ }^{3}$, Wonsik Kim ${ }^{1}$, Motoki Nishimori ${ }^{1}$ \\ ${ }^{1}$ Institute for Agro-Environmental Sciences, National Agriculture and Food Research Organization, Tsukuba, \\ Ibaraki 305-8604, Japan \\ ${ }^{2}$ Japan International Research Center for Agricultural Sciences, Tsukuba, Ibaraki 305-8686, Japan \\ ${ }^{3}$ Policy Research Institute, Ministry of Agriculture, Forestry and Fisheries, Chiyoda-ku, Tokyo 100-0013, Japan
}

\begin{abstract}
Adaptation will be essential in many sectors, including agriculture, as a certain level of warming is anticipated even after substantial climate mitigation. However, global adaptation costs and adaptation limits in agriculture are understudied. Here, we estimate the global adaptation cost and residual damage (climate change impacts after adaptation) for maize, rice, wheat and soybean using a global gridded crop model and empirical production cost models. Producers require additional expenditures under climate change to produce the same crop yields that would be achieved without climate change, and this difference is defined as the adaptation cost. On a decadal mean basis, the undiscounted global cost of climate change (adaptation cost plus residual damage) for the crops are projected to increase with warming from US\$63 billion (B) at $1.5^{\circ} \mathrm{C}$ to $\$ 80 \mathrm{~B}$ at $2^{\circ} \mathrm{C}$ and to $\$ 128 \mathrm{~B}$ at $3^{\circ} \mathrm{C}$ per year. The adaptation cost gradually increases in absolute terms, but the share decreases from $84 \%$ of the cost of climate change (\$53 B) at $1.5^{\circ} \mathrm{C}$ to $76 \%(\$ 61 \mathrm{~B})$ at $2^{\circ} \mathrm{C}$ and to $61 \%(\$ 78 \mathrm{~B})$ at $3^{\circ} \mathrm{C}$. The residual damage increases from $16 \%(\$ 10 \mathrm{~B})$ at $1.5^{\circ} \mathrm{C}$ to $24 \%$ $(\$ 19 \mathrm{~B})$ at $2^{\circ} \mathrm{C}$ and to $39 \%(\$ 50 \mathrm{~B})$ at $3^{\circ} \mathrm{C}$. Once maintaining yields becomes difficult due to the biological limits of crops or decreased profitability, producers can no longer bear adaptation costs, and residual damages increase. Our estimates offer a basis to identify the gap between global adaptation needs and the funds available for adaptation.
\end{abstract}

KEY WORDS: Crop model · Production cost

\section{INTRODUCTION}

Investments in adaptation and high-yielding technology and management are key to maintaining the yield growth of major crops at rates necessary to keep pace with increasing demand (Lobell \& Gourdji 2012, Iizumi et al. 2017a, Zhu et al. 2018). However, adaptation often requires additional inputs of water, fertilizer, chemicals, fuel, labor, machinery and equipment (Porter et al. 2014, Delcour et al. 2015, Kabir et al. 2017, Brown et al. 2019, Iizumi 2019), which represent additional production costs for producers. International adaptation funding and investment

\footnotetext{
*Corresponding author: iizumit@affrc.go.jp
}

can help producers in vulnerable regions across the world adapt to climate change. Thus, there is a need for a better assessment of global adaptation costs, funding and investments to identify the gap between global adaptation needs and funds available for adaptation (Chambwera et al. 2014).

Evidence is scarce, but Wreford \& Renwick (2012) suggested that agricultural global adaptation costs between 2010 and 2050 would account for US\$ 4-166 billion (B) per year. However, the estimates from the World Bank (2006), Stern (2007), UNDP (2007) and Oxfam (2007) studies, which are referred to in Wreford \& Renwick (2012), are not necessarily specific to

() The authors 2020. Open Access under Creative Commons by Attribution Licence. Use, distribution and reproduction are unrestricted. Authors and original publication must be credited. 
agriculture (Chambwera et al. 2014). More sectorspecific estimates are found in the UNFCCC (2007) and World Bank (2010) studies that estimated the global adaptation costs specific to agriculture, forestry and fisheries at \$14 B in 2030 (UNFCCC 2007) and $\$ 7.1-7.3$ B in 2050 (World Bank 2010).

However, $\mathrm{CO}_{2}$ fertilization and impacts due to climate extremes are not considered in the World Bank (2010) study. More importantly, the reported adaptation costs in the World Bank (2010) study are for agricultural and directly related investments in public agricultural research and development (R\&D), irrigation efficiency and expansion, and rural road construction. Therefore, the costs of autonomous adaptation, such as those incurred by producers and traders, are not included in the World Bank (2010) study. In the UNFCCC (2007) study, of $\$ 14 \mathrm{~B}, \$ 11 \mathrm{~B}$ is allocated to purchasing new capital (e.g. to irrigate areas), adopt new practices and move processing facilities, and the remaining \$3 B is used for research and extension activities to facilitate adaptation. Although these are the most widely accepted global adaptation cost estimates for agriculture, it is unclear how much adaptation funding is needed for producers worldwide to adjust their agronomic practices.

The estimates mentioned above give policymakers a sense of the scale of global adaptation costs, and are potentially useful in international negotiations to provide funding and investments for adaptation. However, existing estimates do not show how agricultural adaptation costs and residual damage change with warming. In particular, no estimate relevant to the recent global temperature targets $(2$ and $1.5^{\circ} \mathrm{C}$ ) (UNFCCC 2018) has been presented, while the differences in yield impacts between the 2 warming levels have increasingly become available (Schleussner et al. 2016, Iizumi et al. 2017a, Hoegh-Guldberg et al. 2018).

Here, we present the adaptation cost for, and residual damage to, global crop production under projected climate change. Empirical models that link the production cost to yield and indicators of technology and management level were developed and used to estimate production cost changes due to adaptation. Four major crops (maize, rice, wheat and soybean, which together comprise the vast majority of caloric production in the world) were studied, and 52 crop-producing countries across the world, which together account for $>90 \%$ of the current global harvested area and production, were considered (Table S1 in the Supplement at www.int-res. com/articles/suppl/c080p203_supp.pdf). In this study, the considered adaptation is a producer's private, incremental approach rather than a governmentplanned approach or more transformative adaptation (Marshall et al. 2014, Panda 2018). Therefore, the adaptation aims to maintain current crop types and production systems rather than consider more transformative changes in land use.

\section{METHODS}

Fig. 1 shows the data flow for how we converted emissions, climate and socioeconomic scenarios into adaptation cost and residual damage using a crop model, production cost models and other inputs. The key steps in the data flow are described in the remainder of this section; definitions of adaptation cost and residual damage (Section 2.1), production cost models (Section 2.2) and the calculation of adaptation costs and residual damage (Section 2.3) as well as simulated yields (Section 2.4) are described. Finally, the uncertainty analysis (Section 2.5) is discussed.

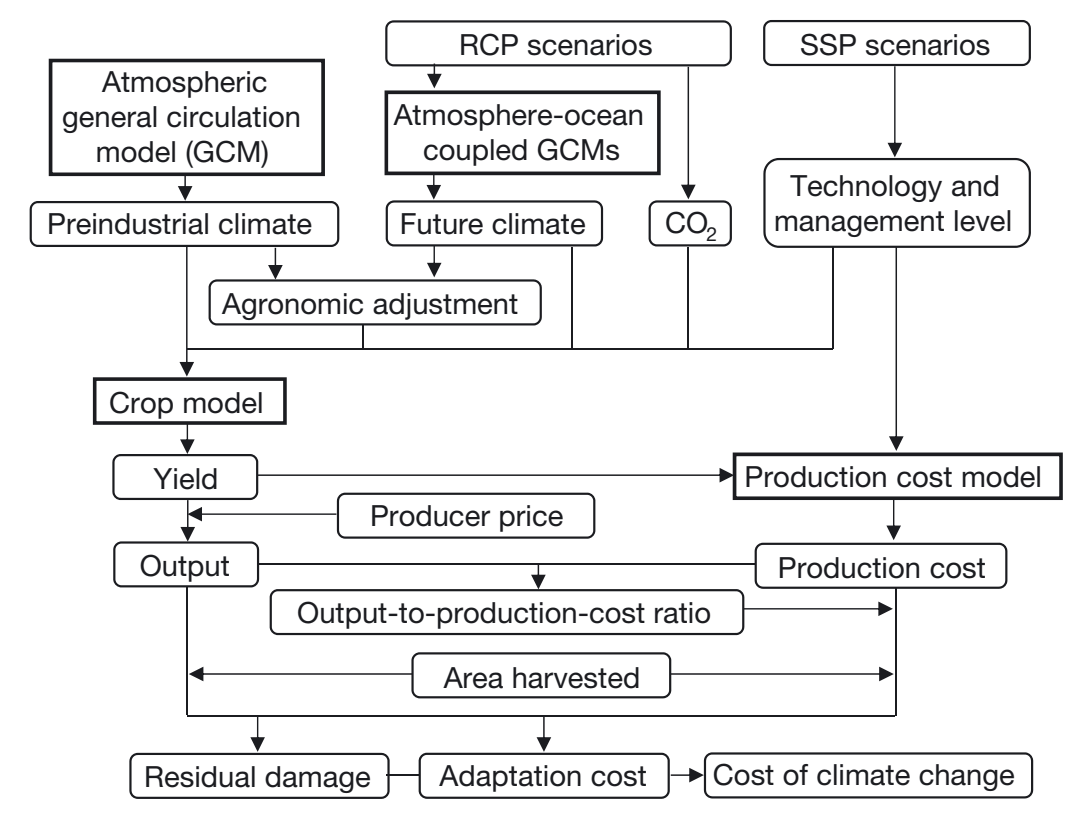

Fig. 1. Data flow used in this study to estimate the adaptation cost and residual damage using emissions, climate and socioeconomic scenarios, as well as crop models, production cost models and other inputs. SSP: shared socioeconomic pathway 


\subsection{Definitions of adaptation cost and residual damage}

Fig. 2 illustrates the definitions of adaptation cost and residual damage as well as the relationship between production cost and yield. We assume that yield increases with an increase in production costs and then levels off. This relationship was common across 2 scenarios: one without climate change and the other with climate change and its associated agronomic adjustments. Sowing date shifts and cultivar switching are considered in the crop model as agronomic adjustments, which are taken as cost-free adaptation. Other agronomic adjustments, such as increases in fertilizer, water, chemicals, fuel, labor, machinery and equipment use, elevate production costs. The aggregated effect on yield from these agronomic adjustments is referred to as adaptation with a cost, and this cost is considered in the production cost models. The average technology and management abilities of producers within a country are indicated by how the socioeconomic scenario changes the yield response to production cost (represented by the production cost and yield curves in Fig. 2). However, the socioeconomic scenario used does not explicitly appear in Fig. 2 because the scenarios between the 2 curves are maintained as the same when calculating the yield impact, adaptation cost and residual damage.
Once a specific form of the production cost and yield curves is determined, the adaptation cost $\left(C^{*}-C_{\text {fact }}\right.$ in Fig. 2; US\$ ha $\left.{ }^{-1}\right)$ is defined as the additional expenditures required by producers to produce a target yield under climate change. The target yield is what would be achieved without cli-

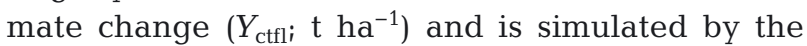
crop model using preindustrial climate conditions as the input, which is described in Section 2.4.2. If the additional expenditures of the producers no longer increase yield due to the biological limits of the crops, then the difference in the yield between $Y_{\text {ctfl }}-Y^{*}$ is defined as the residual damage in $\mathrm{t} \mathrm{ha} \mathrm{h}^{-1}$. The residual damage is also calculated when additional expenditures no longer maintain the current output to production cost ratio (an indicator of profitability; see Section 2.3 for more calculation details). The residual damage in $\mathrm{t} \mathrm{ha}^{-1}$ is converted into that in US\$ ha ${ }^{-1}$ by multiplying the producer price in US\$ $\mathrm{t}^{-1}$ to have a consistent unit with that of the adaptation cost. These calculations are conducted for each country and socioeconomic scenario considered.

If the yield under climate change with cost-free adaptation is higher than the target yield $\left(Y_{\mathrm{ctfl}}\right)$, which could occur at higher latitudes or due to $\mathrm{CO}_{2}$ fertilization, then the residual damage has a negative value and is interpreted as a benefit of climate change. In

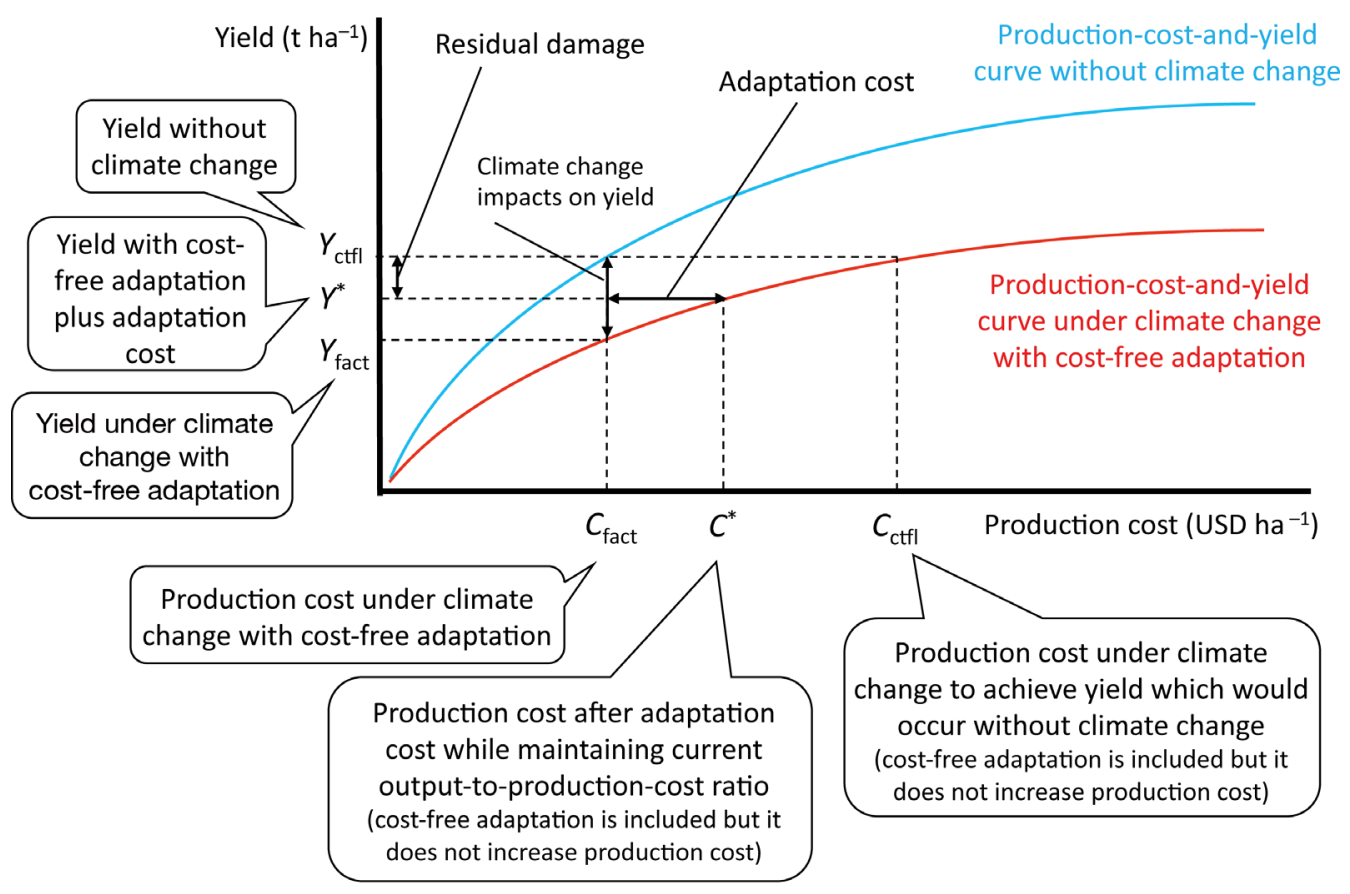

Fig. 2. Production cost, decadal mean yield, adaptation cost and residual damage. The production cost and yield curves shown here are computed for each country and socioeconomic scenario considered 
addition, the adaptation costs range from zero to a positive value and indicate a burden for producers. The sum of the adaptation costs and residual damage is referred to as the cost of climate change. A positive and a negative value of the cost of climate change indicate a net loss and a net benefit for producers, respectively. These definitions are specifically tailored to the agricultural context but are in line with those used in earlier works (Stern 2007, Wreford \& Renwick 2012, Chambwera et al. 2014).

\subsection{Production cost models}

\subsubsection{General description}

We assume that crop production per unit area (yield) is a function of inputs represented by production cost and indicators of technology and management level. Here, we employ the following function as an analogy of the Cobb-Douglas production function used to describe relationships between inputs and outputs (e.g. Rosas 2011):

$$
Y_{t-9: t}=I_{t} A C_{t}^{\alpha} R_{\mathrm{t}}^{\beta}
$$

where $t$ indicates the year, $Y$ is the country decadal mean yield for the period from $t-9$ to $t$ ( $\left.\mathrm{tha}^{-1}\right), I$ is the climate change impact on the yield for a country (dimensionless), $C$ is the annual production cost of a country (US\$ ha ${ }^{-1}$ ), $R$ is the agricultural knowledge stock that represents the average technology and management level adopted by producers within a country (thousand US\$), $A$ is the scale coefficient, and $\alpha$ and $\beta$ are the output elasticity of production cost and knowledge stock, respectively. $Y, I, A, C, \alpha$ and $\beta$ are crop specific, whereas $R$ is common across crops. As yields vary yearly, which is mainly due to weather and climate in the growing season, longterm mean yields are more relevant than annual yields in terms of associations with production costs, which fluctuate less than yields fluctuate yearly.

The knowledge stock is calculated as the sum of the annual governmental expenditures for agricultural R\&D since 1961 with a certain obsolescence rate:

$$
R_{t}=E_{t-6}+(1-\delta) R_{t-1}
$$

where $E$ is the country annual governmental agricultural R\&D expenditure (US\$), $\delta$ is the obsolescence rate of technological knowledge (0.1), and a lag time of 6 yr between research and technology adoption by producers $(t-6)$ is used according to previous work
(Griliches \& Mairesse 1984, Ito 1992, Iizumi et al. 2017a). Country annual governmental agricultural R\&D expenditures are calculated as follows:

$$
E_{t}=G D P_{t} \frac{A G V_{t}}{100} \frac{R D E_{t}}{100}
$$

where GDP is the country annual gross domestic product (US\$), AGV is the country annual agriculture value added ( $\%$ of GDP) and RDE is the country annual total R\&D expenditure (\% of GDP). More sophisticated methods in modeling the contributions of R\&D to yield growth are found (e.g. Fuglie 2018), but we use the simple method because, in general, only a few variables are available in future socioeconomic scenarios.

The climate change impacts on yield are calculated as follows:

$$
I_{t}=\frac{Y_{\text {fact }, t-9: t}}{Y_{\text {ctfl }, t-9: t}}
$$

where $Y_{\text {fact }}$ and $Y_{\text {ctfl }}$ are the simulated decadal mean yield for the period from $t-9$ to $t$ with and without climate change $\left(\mathrm{t} \mathrm{ha}^{-1}\right)$, which are referred to as the factual and counterfactual yields, respectively (Fig. 2). The ecophysiological process-based crop model, which is described in Section 2.4.1, simulates these yields. Changes in air temperature, precipitation, insolation, humidity and soil wetness detectable from daily weather inputs and elevated $\mathrm{CO}_{2}$ are incorporated into these yields. More details are available in Section 2.4.

By solving Eq. (1) in terms of $C$, we obtain the following expression:

$$
C_{t}=\exp \left[\frac{\log \left(\frac{Y_{t-9: t}}{I_{t} A R_{t}^{\beta}}\right)}{\alpha}\right]
$$

which is the form of the production cost model used in this study that enables us to calculate the production costs from the simulated yields and socioeconomic scenarios.

\subsubsection{Data}

The production cost model is calibrated using historical data. The data include the reported annual country production costs ( $C$ in Eq. 5) as well as the reported country annual GDP, GDP shares of agriculture value added and total R\&D expenditure (GDP, AGV and RDE, respectively, in Eq. 3) and simulated country decadal mean factual and counterfactual 
yields ( $Y_{\text {fact }}$ and $Y_{\text {ctfl, }}$ respectively, in Eq. 4). The reported country decadal mean yields calculated from annual data available in the Food and Agriculture Organization of the United Nations (FAO) statistical database (www.fao.org/faostat/en/\#home) are also used ( $Y$ in Eq. 5).

The annual country crop-specific production costs are collected from 2 data sources. One source is the individual country cost reports in which the annual time series during 1991-2010 are available. The number of countries varies by crop (18 for maize, 7 for soybean and rice, and 27 for wheat), and the number of years range from 1 to 20 depending on the crops and countries (Table S2). The other source is the Global Trade Analysis Project (GTAP) 9 database, in which the production costs for 140 countries and regions in 2011 are available (Aguiar et al. 2016). As the GTAP database reports production costs for unskilled labor, skilled labor, capital, land and chemicals (and value output) in million US\$, the total costs are calculated and then divided by the FAO harvested area in 2011 to obtain the production cost in US\$ $\mathrm{ha}^{-1}$. We assume that the 'oil seeds and oleaginous fruit' and 'wheat and meslin' categories in the GTAP database represent soybean and wheat, respectively.

The reported country annual GDP, GDP shares of agriculture value added and total R\&D expenditure for the 1960-2015 period are obtained from the World Bank database (http://data.worldbank.org/ data-catalog/world-development-indicators). The details of the simulated yields are available in Section 2.4. In brief, these yields are aggregated from annual values at $0.5^{\circ}$ resolution to decadal mean values at the country level and then bias corrected against the FAO-reported yields.

\subsubsection{Specifications and calibration}

Three specifications of the production cost model are established using different production cost datasets for the model calibration: (1) 'time series' based on the cost reports of the individual countries (2) 'cross-sectional' calibration using the GTAP 9 database and (3) 'panel' based on the 2 datasets. The time series specification is calibrated for each country and crop, while a single global model is established for each of the cross-sectional and panel specifications from one crop to another. Such specifications are often adopted to estimate climate change impacts, and it is well documented that they respond differently to projected climate (Lobell \& Burke 2010, Zhou \& Turvey 2014).
For the model calibration, the Metropolis-Hastings algorithm of the Markov chain Monte Carlo (MCMC) method (Metropolis et al. 1953, Hastings 1970, Iizumi et al. 2009) is used (see also Appendix). The MCMC has 30000 steps with 6 parallel chains. The convergence is determined by Gelman and Rubin statistics (<1.1; Gelman \& Rubin 1992) after a burn-in of 10000 . Convergence is observed for all cases of the cross-sectional and panel specifications and for most cases of the time series specification. The prior and posterior distributions of $A, \alpha$ and $\beta$ used in the MCMC method are shown in Table S3.

\subsection{Calculation of adaptation cost and residual damage}

The procedure to calculate the adaptation cost and residual damage is described below. First, a given specification of the production cost model gives a specific form of the production cost and yield curves in Fig. 2. If the country decadal mean counterfactual yield is higher than the factual yield $\left(Y_{\mathrm{ctfl}}>Y_{\mathrm{fact}}\right)$, then climate change negatively affects yield. Using the production cost model, we address a yield level, $Y^{*}$, that fell within the interval from $Y_{\text {fact }}$ to $Y_{\text {ctfli }}$ simultaneously, the output to production cost ratio is equal to or higher than the current levels. This yield level corresponds to the yield with cost-free adaptation plus adaptation with a cost in Fig. 2.

To determine the production cost under climate change with cost-free adaptation plus adaptation with a cost $\left(C^{*}\right)$ for a given crop, country and year, a possible decadal mean yield value, $Y^{\prime}$, that falls within the interval from $Y_{\text {fact }}$ to $Y_{\text {ctrl }}$ is fed into the production cost model. The simulated production cost $\left(C^{\prime}\right)$ and the input yield $\left(Y^{\prime}\right)$ are also used to calculate the output to production cost ratio when adaptation with a cost examined is adopted $\left(F^{\prime}\right)$. This procedure is done using Eq. (6), which is described below $\left(F^{\prime}=O Y^{\prime} / C^{\prime}\right)$. If $F^{\prime} \geq F$, then $Y^{\prime}$ and $C^{\prime}$ are accepted as $Y^{*}$ and $C^{*}$. If not, $Y^{\prime}$ is changed to a smaller value than the previous value, and $F^{\prime}$ is calculated again. This calculation is iterated from $F^{\prime}=Y_{\text {ctfl }}$ to $Y^{\prime}=Y_{\text {fact }}$ with a step of $0.01 \mathrm{tha}^{-1}$.

The output to production cost ratio $(F)$ is calculated as follows:

$$
F_{t}=\frac{O Y_{\text {fact, }, t-9: t}}{C_{t}}
$$

where $O$ is the FAO country average producer price in 2005-2009 (US\$ t ${ }^{-1}$ ), $Y_{\text {fact }}$ is the simulated country decadal mean factual yield $\left(\mathrm{t} \mathrm{ha}^{-1}\right)$, and $C$ 
is the country annual production cost $\left(\mathrm{US} \$ \mathrm{ha}^{-1}\right.$ ), derived by inputting the country decadal mean factual and counterfactual yields $\left(Y_{\text {fact }}\right.$ and $\left.Y_{\text {ctfl }}\right)$ and the country annual knowledge stock $(R)$ into the production cost model. $Y_{\text {fact }}$ is used as $Y$ in Eq. (5) unless otherwise noted. Crop production is generally profitable, as the output to production cost ratio of $>1$ indicates, with some unprofitable countries and years occurring mainly due to interannual variations in yields and in the input and output prices and smallholder subsistence farming (Fig. S1 in the Supplement).

The adaptation cost is calculated as follows:

$$
A_{t}=\left(C_{t}^{*}-C_{\text {fact }, t}\right) H
$$

where $A$ is the country annual adaptation cost (US\$); $C^{*}$ and $C_{\text {fact }}$ are the production costs to produce $Y^{*}$ and $Y_{\text {fact }}\left(\mathrm{US} \$ \mathrm{ha}^{-1}\right)$, respectively; and $H$ is the FAO country area harvested in 2010 (ha). The term $\left(C^{*}-\right.$ $C_{\text {fact }}$ ) indicates the additional expenditures of producers for adaptation with a cost. If $Y^{*}<Y_{\text {ctfl, }}$ then it indicates that the additional expenditures for adaptation that exceed the level of $C^{*}$ do not maintain the current output to production cost ratio and decrease profitability. In this case, the residual damage is calculated as follows:

$$
D_{t}=\left(Y_{\mathrm{ctfl}, t-9: t}-Y^{*}\right) H O
$$

where $D$ is the country annual residual damage (US\$), $Y_{\text {ctfl }}$ is the country decadal mean counterfactual yield $\left(\mathrm{t} \mathrm{ha}^{-1}\right)$, and $Y^{*}$ is the country decadal yield with cost-free adaptation plus adaptation with a cost $\left(\mathrm{t} \mathrm{ha}^{-1}\right)$. If the factual yield is higher than the counterfactual yield $\left(Y_{\text {fact }}>Y_{\text {ctrl }}\right)$, we set $Y^{*}=Y_{\text {fact, }}$ which leads to an adaptation cost of zero $\left(C^{*}=C_{\text {fact }}\right.$ in Eq. 7) and a negative value of $D\left(Y_{\text {fact }}=Y^{*} \geq Y_{\text {cttl }}\right.$ in Eq. 8), which is interpreted as a benefit of climate change. Then, the adaptation cost and residual damage are summed as follows:

$$
S_{t}=A_{t}+D_{t}
$$

where $S$ is the country's annual cost of climate change (US\$). The country's annual adaptation cost, residual damage and cost of climate change are calculated by crop and aggregated for the 4 crops. The crop-aggregated country annual estimates across the 52 countries are added to determine global annual values. Decadal mean values are calculated and used for the analysis. No discount rate is considered in this study.

\subsection{Simulated yields}

\subsubsection{Global gridded crop model}

The global gridded crop model CYGMA (Iizumi et al. 2017a, 2018, Fujimori et al. 2018, Sultan et al. 2019, Takakura et al. 2019) is used for this study. The model operates at a daily time step and simulates grid-cell yields under rainfed and irrigated conditions separately at $0.5^{\circ}$ resolution. In the model, crop development is calculated as a fraction of the accumulated growing degree-days relative to the crop thermal requirements. For wheat, only spring wheat is considered because the vernalization process is not considered in the current model version. Leaf growth and senescence are calculated according to the fraction of the growing season using the prescribed shape of the leaf area index curve. Yields are calculated from the photosynthetically active radiation intercepted by the crop canopy, the radiation-use efficiency, the $\mathrm{CO}_{2}$ fertilization on the efficiency and the fraction of total biomass increments allocated to the harvestable component. The soil water balance submodel, which is coupled with the snow cover submodel, is used to calculate actual evapotranspiration. $\mathrm{N}$ deficits, heat, cold, water deficits and water excesses are considered, and the most dominant stress type for a day decreases the daily potential increment in leaf area and yield. All the stress types except $\mathrm{N}$ deficits are functions of daily weather.

As noted, the knowledge stock is calculated from the socioeconomic scenario (Eqs. $2 \& 3$ ), and in the crop model, it is translated into the use of improved technologies and management systems on farm fields (that is, high-yielding technology and management). Improved varieties are central to new technologies, but we do not exclude other technologies, because the literature reports that improved varieties explain one-fourth to one-half of the past yield growth, and improved management, including the increased use of irrigation, chemicals and machinery, as well as improved input-use efficiency are the reasons for the remaining portion of the yield growth (Herdt \& Capule 1983, Jones 2013, Iizumi et al. 2017a). Therefore, in the model, the crop's tolerance to the 5 stresses mentioned earlier increases as the knowledge stock increases. The contributions of the increased use of synthetic fertilizers to yield are separately considered. $\mathrm{N}$ application rates increase and level off according to the changes in a country's annual per capita GDP and per capita agricultural area. Therefore, the $\mathrm{N}$ application rates are not directly associated with the knowledge stock, although these 
2 variables are based on a common GDP scenario. We assume that the use of high-yielding technology and management increases production costs.

Sowing dates are updated annually in response to changes in temperature and moisture regimes for the last decade. Crop thermal requirements are also updated annually based on the decadal mean temperature, which represents the use of longer-season cultivars to prevent yield losses associated with shortened crop durations. We assume that sowing date shift and cultivar switching are cost free. More modeling details are available in Iizumi et al. (2017a), and an in-depth validation can be found in Iizumi et al. $(2017 \mathrm{a}, 2018)$.

\subsubsection{Crop model simulations}

Two types of crop simulations are performed by the CYGMA model (Table 1). One is factual run simulated yields under climate change with sowing date shift and cultivar switching. The other simulation is counterfactual run simulated yields without climate change. In both runs, annual yields are simulated for the 1961-2100 period.

For the factual run, the following settings are utilized: bias-corrected CMIP5 general circulation model (GCM) daily outputs (lizumi et al. 2017b; Table S4); global annual mean atmospheric $\mathrm{CO}_{2}$ concentrations from the RCPs (van Vuuren et al. 2011) to consider $\mathrm{CO}_{2}$ fertilization; the diffusion of conventional highyielding technology and management in developing countries that are already available in developed countries, which are established using the shared socioeconomic pathways (SSPs; O'Neill et al. 2014); and irrigation intensity (the ratio between irrigated and harvested areas) in 2010. Technology and management, which further increase yields in developed countries where yields are already high, are not considered. Future changes in irrigation intensities are also not considered. Currently, scenarios on technology and management are not available, despite existing efforts (Valdivia et al. 2015).

The country annual GDP scenarios are obtained from the International Institute for Applied Systems Analysis (IIASA) Energy Program database (https:// tntcat.iiasa.ac.at $/ \mathrm{SspDb} / \mathrm{dsd}$ ?Action=htmlpage\&page= about). The SSP scenarios represent the following different socioeconomic assumptions: (1) sustainability, medium-high economic growth and low population number; (2) 'middle-of-the-road', intermediate economic growth and intermediate population number; (3) fragmentation, slow economic growth and very high population number; (4) inequality, slow economic growth and high population number; and (5) conventional development, high economic growth and low population number (van Vuuren et al. 2014). The GDP shares of agriculture value added and the total R\&D expenditure for the future period are set to be the same as those in 2010 throughout the future period. This assumption may be unrealistic for some regions, especially in the developing world, because the GDP share of agriculture decreases with economic growth and the development of new highyielding technology and management becomes increasingly difficult and costly in regions where yields are already high (Beintema et al. 2012), but such a scenario is not available.

For the counterfactual run, we used the Meteorological Research Institute atmospheric general circulation model (AGCM) version 3.2 (MRI-AGCM3.2)

Table 1. Crop model simulations used in this study. GCM: general circulation model; AGCM: atmospheric general circulation model; SSP: shared socioeconomic pathway

\begin{tabular}{|c|c|c|c|c|c|}
\hline Run & Climate & $\mathrm{CO}_{2}$ & Agronomic adjustment & Technology and management & Period \\
\hline Factual $^{\mathrm{a}}$ & $\begin{array}{l}\text { Bias-corrected } \\
\text { CMIP5 GCM } \\
\text { outputs }\end{array}$ & $\begin{array}{l}\text { RCPs }(2.6,4.5,6.0 \\
\left.\text { and } 8.5 \mathrm{~W} \mathrm{~m}^{-2}\right)\end{array}$ & $\begin{array}{l}\text { Considered (sowing } \\
\text { date shifting and culti- } \\
\text { var switching) }\end{array}$ & $\begin{array}{l}\text { N application rate and agricultural } \\
\text { knowledge stock change depending } \\
\text { on SSP }(1,2,3,4 \text { and 5); irrigation inten- } \\
\text { sity is set as a constant, the } 2010 \text { level }\end{array}$ & $1961-2100$ \\
\hline Counterfactual $^{\mathrm{b}, \mathrm{c}}$ & $\begin{array}{l}\text { Bias-corrected } \\
\text { AGCM nonwarming } \\
\text { climate simulation }^{\mathrm{d}}\end{array}$ & $\begin{array}{l}287 \text { ppm } \\
\text { (year } 1850 \text { level) }\end{array}$ & Considered & $\begin{array}{l}\mathrm{N} \text { application rate and agricultural } \\
\text { knowledge stock change depending } \\
\text { on SSP }(1,2,3,4 \text { and 5); irrigation inten- } \\
\text { sity is set as a constant, the } 2010 \text { level }\end{array}$ & $1961-2100$ \\
\hline \multicolumn{6}{|c|}{$\begin{array}{l}\text { a Results presented in lizumi et al. }(2017 \mathrm{a}) \\
{ }^{\mathrm{b}} \text { Runs conducted in this study; } 120 \mathrm{yr}(1958-1959 \times 60) \text { spin-up simulation results conducted in Iizumi et al. }(2017 \mathrm{a}) \text { are used as the initial } \\
\text { soil moisture and snow water equivalent conditions } \\
{ }^{\mathrm{c} S i m i l a r} \text { run but for the } 1961-2010 \text { period using the } 100 \text {-member historical and nonwarming climate simulations as presented in Iizumi et } \\
\text { al. }(2018) \\
{ }^{\mathrm{d} C l i m a t e} \text { data for } 1961-2100 \text { randomly resampled from the bias-corrected } 100 \text {-member ensemble AGCM nonwarming climate simu- } \\
\text { lation for 1951-2010; five ensemble members are generated }\end{array}$} \\
\hline
\end{tabular}


(Mizuta et al. 2012) output of nonwarming climate simulations. The bias correction of the AGCM daily output is described in Iizumi et al. (2018) and Sultan et al. (2019). The details of the nonwarming climate simulation are available in Shiogama et al. (2016), Mizuta et al. (2017) and Imada et al. (2017). In brief, the nonwarming climate simulation represents a preindustrial climate that lacks human influences on the global climate system. Sea surface temperature and sea ice, both of which are detrended, as well as the greenhouse gas concentration in 1850, anthropogenic aerosol and volcanic sulfate aerosol in 1850 and ozone concentration in 1961 are used as input to the nonwarming simulation of the climate model.

The bias-corrected AGCM output for the period 1951-2010 (but no anthropogenic climate trend) is resampled and used for the counterfactual run for 1961-2100. Although the 'no climate change' scenario used in Iizumi et al. (2017a) is generated by resampling the retrospective meteorological forcing dataset for 1981-2010, the bias-corrected AGCM nonwarming climate simulation offers more reasonable estimates of preindustrial climates. The $\mathrm{CO}_{2}$ concentration is set to the 1850 level of $287 \mathrm{ppm}$ throughout the study period. Sowing date shift and cultivar switching are considered (Table 1), but almost no change occurs in the counterfactual run because no climate trend occurs. The technology and management scenarios used in the counterfactual run are the same as those used in the factual run.

\subsubsection{Spatial aggregation and bias correction of simulated yields}

Simulated annual yields from the factual and counterfactual runs at $0.5^{\circ}$ resolution are aggregated into country average yields. The extents of rainfed and irrigated areas in 2010 estimated using the 2 datasets (Portmann et al. 2010, Siebert et al. 2015) are used in the aggregation. Decadal mean yields are calculated using the simulated annual yields after spatial aggregation to a country scale. Then, the calculated country decadal mean yields are offset so that their 5 GCM ensemble mean values for the 2001-2010 period become equal to the average of the FAO yields for the same period (see black circles in the upper panels of Fig. S2). The offset used varies by crop, although it is identical throughout the study period and across the factual and counterfactual yields. Therefore, the simulated differences between the factual and counterfactual yields are maintained after being offset. The offset is required to reduce errors in the estimated production costs propagated from errors in the simulated yields.

\subsection{Uncertainty analysis}

It is well documented that projected climate change impacts vary by scenario. Although not an exhaustive list, emissions scenarios (RCPs), climate models (GCMs), socioeconomic scenarios (SSPs), production cost models (time series, cross-sectional and panel specifications), countries and crops are expected to be the main sources of uncertainty. ANOVA is powerful for partitioning the observed variance in a particular variable into components attributable to different sources of variation (Chambers \& Hastie 1991). For this reason, multiple studies have adopted ANOVA for climate change studies (Hawkins \& Sutton 2009, Vermeulen et al. 2013, Nelson et al. 2014, Müller et al. 2015, Iizumi et al. 2017b, Takakura et al. 2019).

In this study, the target variables include yield impact, adaptation cost, residual damage and cost of climate change. In the global crop-aggregated ANOVA, the variable responses are assessed for effect by emissions scenario $(\mathrm{n}=4)$, climate model $(\mathrm{n}=5)$, socioeconomic scenario $(\mathrm{n}=5)$ and production cost model $(\mathrm{n}=2$; cross-sectional and panel specifications). The effect by country $(\mathrm{n}=3)$, crop type $(\mathrm{n}=4)$ and production cost model $(\mathrm{n}=3$; time series specification in addition to the remaining 2) are additionally considered for the country- and crop-specific ANOVA. ANOVA is conducted by time frame, as in earlier studies, to depict changes in major sources of uncertainty over time. We use the statistical package $\mathrm{R}$ version 3.5.0 (aov function; R Development Core Team 2014). The sum of the squared error indicates the magnitude of total variance attributed to each source, with the remaining variance allocated to the residuals. The mean square error adjusts for the number of items in each source and provides an indication of the relative contributions of each source to the total variance in the target variables.

\section{RESULTS}

\subsection{Simulation of current production costs}

The production cost models are successfully calibrated. If the time series specification results are taken as the example for explanatory purposes, then 
the Pearson's correlation coefficient calculated between the reported and reproduced values ranges from 0.815 to 0.986 ( $\mathrm{n}=93-238 ; \mathrm{p}<0.001)$. The RMSE varies among the crops from 50 to $205 \mathrm{US} \mathrm{ha}^{-1}$, and these RMSE values correspond to $11-30 \%$ of the multicountry, multiyear average of the reported data (Fig. 3).

The production cost responses established using the cross-sectional and panel specifications resemble those of the time series - the simulated production costs increase as the country decadal mean yields increase, with variations by specification (Fig. S3). In comparison with the cross-sectional and panel specifications, the time series specification often results in higher production costs (this tendency is prominent for soybean; Fig. S3). The simulated production costs for soybean and rice from the panel specification are almost always smaller than those from the cross-sectional specification, while the difference between the 2 specifications is negligibly small for maize and wheat.
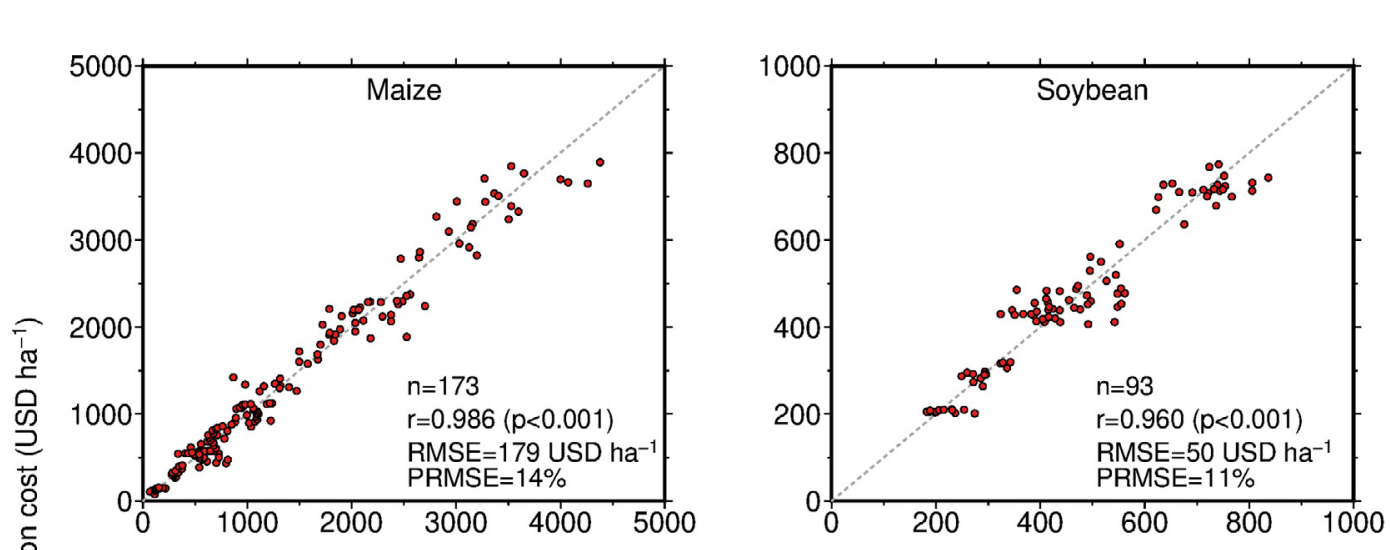

The simulated yield impacts under projected climate and $\mathrm{CO}_{2}$, relative to preindustrial conditions, largely vary by crop. The global decadal mean factual yields of maize and soybean are almost always lower than their counterfactual yields (upper panels of Fig. S2). For rice and wheat, however, the factual and counterfactual yields are similar. These yield impacts lead to overall increases in production costs under climate change, with different amplitudes for different crops (lower panels of Fig. S2). Similar yield impacts as those presented here are found in Iizumi et al. (2017a), who analyzed the same factual run outputs as those in the present study. Iizumi et al. (2017a) note that the different photosynthetic pathways across crops (C4 for maize versus C3 for rice, wheat and soybean) contribute to the different yield impacts across the crops, as do the intercrop differences in optimal temperature range in modeling crop

\subsection{Yield impact, adaptation cost and residual damage}

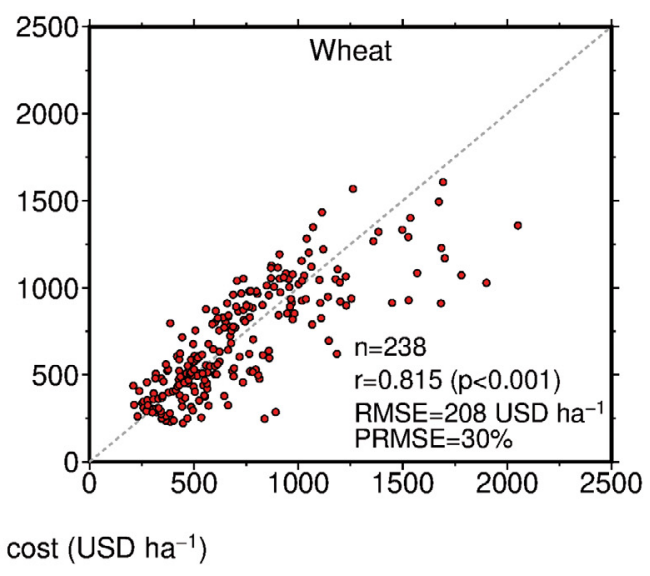

Fig. 3. Correspondence between reported and simulated production costs. Data derived from the time series production cost models are presented. Points represent the annual production cost of a crop of interest in individual countries ( $C$ in Eq. 5) for the 1991-2010 time period. Sample size (n), correlation (r), p-value, RMSE and RMSE normalized against the mean of the reported data (PRMSE) are presented. Countries with $n>3$ are presented here 
phenological development and heat stress for leaf area growth and yield formation (rice has a higher value than the remaining crops), geographic distribution of harvested area (wheat in higher latitudes receives benefits from climate change), irrigation intensity, and future economic growth in countries where yields are currently low.

Based on a multiscenario ensemble mean, the adaptation cost is projected to gradually increase with time. The global decadal mean adaptation cost is almost the same across the low (RCP2.6) and high (RCP8.5) emissions scenarios and accounts for $\$ 68-70 \mathrm{~B}$ in 2041-2050 and \$91-94 B in 2091-2100 per year, respectively (red and blue solid lines in Fig. 4a). In contrast, the global decadal mean residual damage under the high emissions scenario increases from \$18 B in 2041-2050 to \$177 B in 2091-2100 per year (red solid line in Fig. 4b), whereas under the low emissions scenario, it remains at a certain level over time with a small benefit from climate change $(-\$ 3 \mathrm{~B}$ per year; blue solid line in Fig. 4b). The global decadal mean cost of climate change follows the same pattern of residual damage because the adaptation costs are similar across the 2 emissions scenarios. The projected cost of climate change increases from $\$ 88 \mathrm{~B}$ ( $\$ 65$ B) in 2041-2050 to $\$ 268$ B (\$90 B) in 2091-2100 under the high (low) emissions scenario (Fig. 4c).

These estimates are associated with a global temperature increase from preindustrial levels. The projected decadal ensemble mean global cost of climate change increases from \$63 B (90\% probability interval of $\$ 28-112 \mathrm{~B}$ ) at $1.5^{\circ} \mathrm{C}$ to $\$ 80 \mathrm{~B}(\$ 32-153 \mathrm{~B})$ at $2^{\circ} \mathrm{C}$ and to $\$ 128 \mathrm{~B}$ ( $\$ 63-222 \mathrm{~B}$ ) at $3^{\circ} \mathrm{C}$ per year, with considerable variations by scenario (upper panel of Fig. 5). The decadal ensemble mean global adaptation cost gradually increases with warming in absolute terms from $\$ 53 \mathrm{~B}$ at $1.5^{\circ} \mathrm{C}$ to $\$ 61 \mathrm{~B}$ at $2^{\circ} \mathrm{C}$ and to $\$ 78 \mathrm{~B}$ at $3^{\circ} \mathrm{C}$ per year. However, the share of the adaptation costs decreases from $84 \%(65-98 \%)$ of the cost of climate change at $1.5^{\circ} \mathrm{C}$ to $76 \%(50-97 \%)$ at $2^{\circ} \mathrm{C}$ and to $61 \%$ $(29-96 \%)$ at $3{ }^{\circ} \mathrm{C}$ (green solid and dotted lines in Fig. 5b). The opposite pattern with adaptation cost share is found for the residual damage share, and it increases from $16 \%(2-35 \%)$ of the cost of climate change at $1.5^{\circ} \mathrm{C}$ to $24 \%(3-50 \%)$ at $2{ }^{\circ} \mathrm{C}$ and to $39 \%$ $(4-71 \%)$ at $3{ }^{\circ} \mathrm{C}_{i}$ the corresponding decadal ensemble mean global residual damages are $\$ 10,19$ and $50 \mathrm{~B}$ per year, respectively (pink solid and dotted lines in Fig. 5b). The decrease in the adaptation cost share in global crop production with warming can be explained by the combination of a relatively slow increase in adaptation cost even under the high emissions scenario and the relatively rapid increase in residual damage with warming. These results can be interpreted as follows: once additional production cost expenditures for adaptation no longer maintain the current output to production cost ratio because of the severe negative impacts of climate change and/or the biological limits of crops, producers will stop further spending on adaptation, and the residual damage will start to increase.

\subsection{Sources of uncertainty}

The main source of uncertainty in the variable responses differs by time frame. Global crop-aggregated ANOVA results reveal that in the near future (2041-2050), climate models appear as the largest source of uncertainty for all the target variablesyield impact, adaptation cost, residual damage and cost of climate change (Table 2). Climate models are the most important source of uncertainty for the adaptation cost in the distant future (2091-2100), but
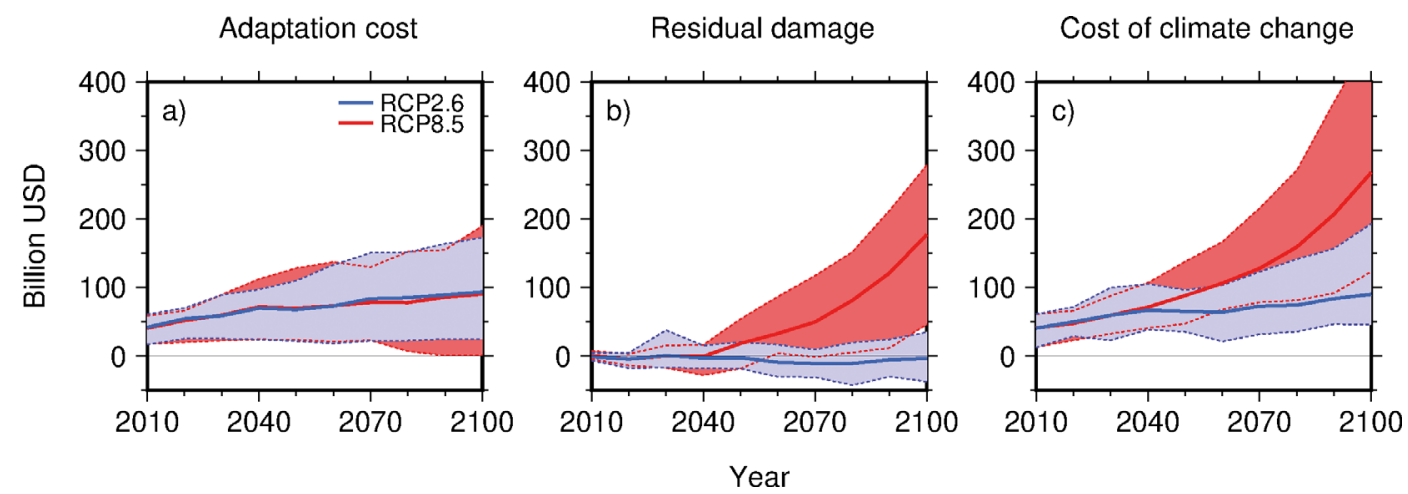

Fig. 4. Projected decadal mean (a) global adaptation cost, (b) residual damage and (c) cost of climate change for the 4 crops under the low (RCP2.6) and high (RCP8.5) emissions scenarios. Panel (c) is the sum of panels (a) and (b). Solid lines indicate the ensemble mean, and shaded areas with dotted lines denote the $90 \%$ probability interval consisting of 50 scenarios (5 climate models $\times 5$ socioeconomic scenarios $\times 2$ production cost models [cross-sectional and panel specifications]) 
emissions scenarios emerge as the largest source of uncertainty for the remaining variables. For both

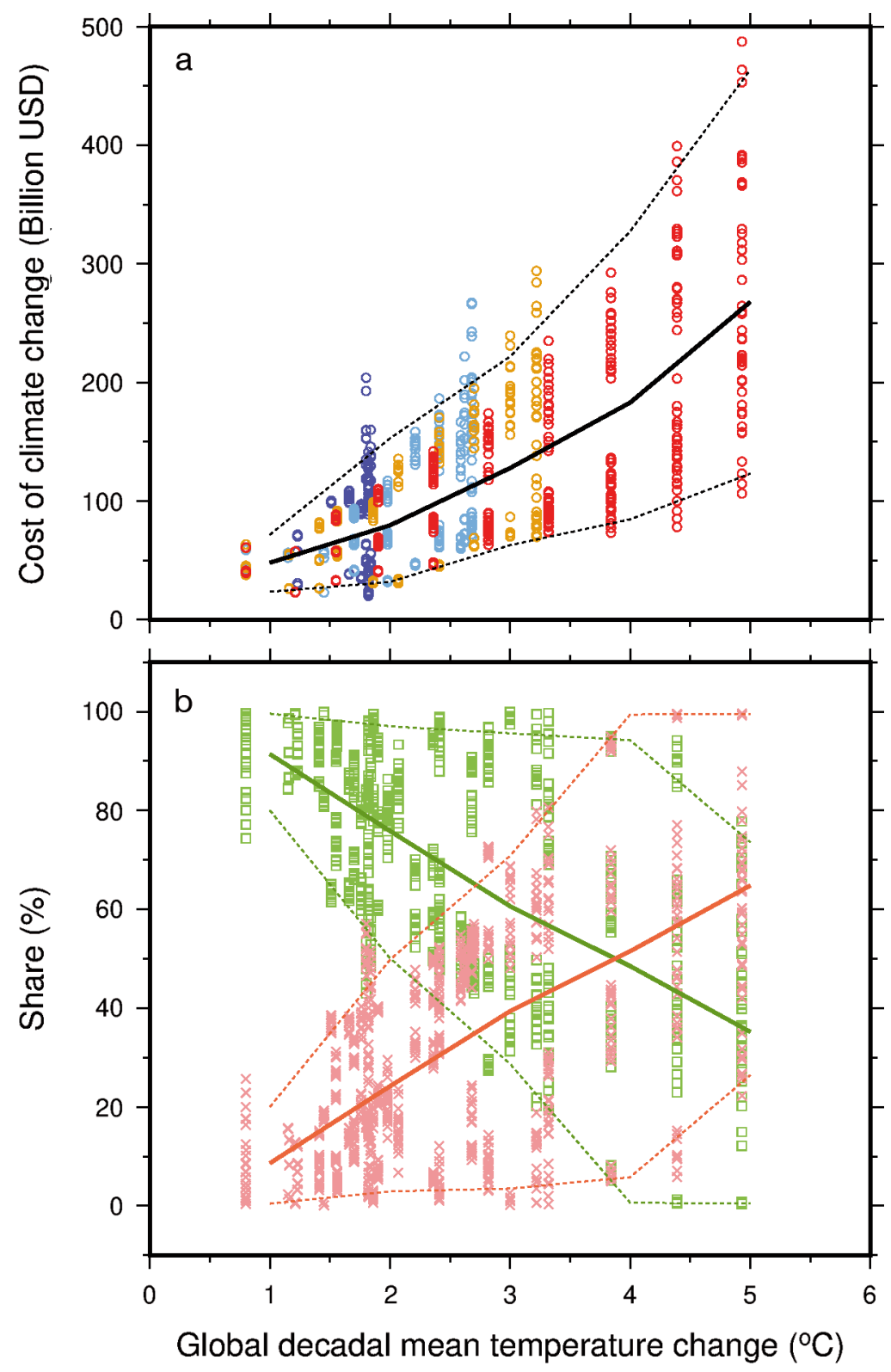

Top panel

- Cost of climate change ( ${ }^{\circ} \mathrm{RCP} 2.6,{ }^{\circ} \mathrm{RCP} 4.5, \circ \mathrm{RCP} 6.0, \circ \mathrm{RCP} 8.5$ ), - Average

Bottom panel

$\square$ Adaptation cost share, - Average, $\times$ Residual damage share, - Average

Fig. 5. (a) Projected decadal mean global cost of climate change and (b) share of the adaptation cost and residual damage for the crops as a function of the global decadal mean temperature change relative to the preindustrial level (1850-1900). Colored solid and dotted lines indicate the average and $90 \%$ probability interval, respectively, calculated from 2000 scenarios (4 emissions scenarios $\times 5$ climate models $\times 5$ socioeconomic scenarios $\times 2$ production cost models [cross-sectional and panel specifications] $\times 10$ decades for the 2001-2100 period), with the $1^{\circ} \mathrm{C}$ bins starting at $0.5^{\circ} \mathrm{C}$ time frames, production cost models (cross-sectional and panel specifications) only moderately contribute to the uncertainty in the determination of adaptation costs and climate change costs because the production cost responses to input yields are similar across the 2 specifications considered here (Fig. S3).

In the country- and crop-specific ANOVA results, country and/or crop type is almost always the most important source of uncertainty for all the target variables considered here, regardless of the time frame (Table S5). Unlike the global crop-aggregated ANOVA results, production cost models appear to be more important than emissions scenarios and climate models in explaining the uncertainty of the estimated adaptation costs and climate change costs. The different production cost responses to input yields for the time series specification compared with the cross-sectional and panel specifications contribute to the result (Fig. S3). This tendency highlights the highly location- and crop-specific nature of adaptation costs.

\section{DISCUSSION}

\subsection{Interpretation and implications}

Recent climate change has already led to global production losses of $\$ 42$ B per year for maize, wheat and soybean (the yield impacts for rice are not significant at the global scale) (Iizumi et al. 2018). The cost of climate change in 2001-2010 estimated in this study (\$41 B) is comparable to this value. In the high emissions scenario, the cost of climate change in the distant future (\$268 B) is approximately 7 -fold higher than that at present; in this scenario, because of the adaptation limits, the residual damage accounts for a predominant portion (66\%) of the cost of climate change, while the adaptation cost makes up a relatively small portion (34\%). In contrast, in the 
Table 2. ANOVA for the projected global decadal mean crop-aggregated yield change, adaptation cost, residual damage and cost of climate change. Significance: $\cdot 10 \% ;{ }^{*} 5 \% ;{ }^{* *} 1 \% ;{ }^{* * *} 0.1 \%$

\begin{tabular}{|c|c|c|c|c|c|}
\hline \multirow{2}{*}{ Variable } & \multirow{2}{*}{$\mathrm{df}$} & \multicolumn{4}{|c|}{ Mean square error } \\
\hline & & Yield impact & Adaptation cost & Residual damage & Cost of climate change \\
\hline \multicolumn{6}{|l|}{ 2041-2050 } \\
\hline Emissions & 3 & $0.309^{* * *}$ & $49.5^{* * *}$ & $359.7^{* * *}$ & $328.6^{* * *}$ \\
\hline Climate model & 4 & $1.321^{* * *}$ & $2427.3^{* * *}$ & $743.8^{* * *}$ & $2298.9^{* * *}$ \\
\hline Socioeconomic & 4 & $0.009^{*}$ & $39.2^{* * *}$ & 0.3 & $35.8^{* * *}$ \\
\hline Cost model & 1 & 0.000 & 10.9 & 3.2 & 2.3 \\
\hline Residuals & 187 & 0.004 & 2.8 & 3.4 & 4.4 \\
\hline \multicolumn{6}{|l|}{ 2091-2100 } \\
\hline Emissions & 3 & $16.699^{* * *}$ & 7 & $20129^{* * *}$ & $19608^{* * *}$ \\
\hline Climate model & 4 & $5.653^{* * *}$ & $5546^{* * *}$ & $6999^{* * *}$ & $12662^{* * *}$ \\
\hline Socioeconomic & 4 & $0.214^{* * *}$ & $1396^{* * *}$ & 117 . & $2302^{* * *}$ \\
\hline Cost model & 1 & 0 & $225^{*}$ & 1 & $253^{*}$ \\
\hline Residuals & 187 & 0.041 & 34 & 51 & 42 \\
\hline
\end{tabular}

low emissions scenario, the cost of climate change is limited to $\$ 90 \mathrm{~B}$ or one-third of that in the high emissions scenario, with the entire cost of climate change attributed to the adaptation cost $(100 \%)$.

Based on these findings, climate change mitigation is essential to enable producers to adapt to climate change using an incremental approach. In the high emissions scenario, the negative impacts of climate change exceed the adaptive capacity of producers based on an incremental approach. Therefore, if climate change follows the high emissions scenario, then national governments, commercial entities and international organizations, in addition to producers, need to incur costs related to agricultural $R \& D$, extension services, subsidies and others to reduce residual damage. The high level of residual damage shown in this study suggests that incremental adaptation is insufficient to address the negative impacts of climate change, and more transformative adaptation, including switching crop types and shifting production areas, will be necessary.

\subsection{Comparison with earlier adaptation cost estimates}

A consistent comparison of the global adaptation costs reported in earlier work is difficult to conduct because of disparities in time frames, scenarios, baselines, coverage of crop types, regions, adaptation measures and methods across studies, as noted in the UNEP (2016) report. Although a consistent comparison is not feasible, UNFCCC (2007) and World Bank (2010) studies offer estimates that are relevant for comparison. The global annual adaptation costs of $\$ 53 \mathrm{~B}$ at $1.5^{\circ} \mathrm{C}$ and $\$ 78 \mathrm{~B}$ at $2^{\circ} \mathrm{C}$ estimated in this study are significantly larger than the other estimated values of $\$ 14$ B in 2030 (UNFCCC 2007) and $\$ 7.1-7.3$ B in 2050 (World Bank 2010). The difference becomes greater if the following 2 facts are considered: first, our estimates are only for 4 crops in 52 crop-producing countries, and second, the estimates from the 2 earlier studies are for not only agriculture but also forestry and fisheries worldwide.

Addressing the exact reasons for discrepancies is a difficult task and beyond the scope of this study. However, we highlight the following possible reasons as a nonexhaustive list. Our study does not consider international trade, while the World Bank (2010) study explicitly considers it, which may reduce global adaptation costs by allocating agricultural commodities from surplus to deficit countries (Baldos \& Hertel 2015, Hasegawa et al. 2016). Preindustrial climate conditions are used as the baseline in our study, whereas the World Bank (2010) study uses climate conditions in the year 2000 as the baseline. Yield impacts become more severe when assessed relative to a climate at preindustrial levels than when assessed relative to a climate in a more recent period, because the global temperature in $2006-2015$ was $0.87^{\circ} \mathrm{C}$ higher than that in the preindustrial period (IPCC 2018).

Accumulated evidence indicates that observed yields have already been affected by climate change (Cramer et al. 2014, Moore \& Lobell 2015, Iizumi et al. 2018, Ray et al. 2019, Sultan et al. 2019). Earlier studies (Nelson et al. 2014, Wiebe et al. 2015) have used exogenous yields, which are extrapolated from observed yield trends, as counterfactuals. However, extrapolated trends from yields under observed climate change may be lower than those from yields without climate change. Therefore, this approach potentially underestimates adaptation costs and re- 
sidual damage, as well as yield impacts, because of the use of lower baseline yield compared to approaches using yields under preindustrial climate conditions as counterfactuals. Our method utilizing the yields under preindustrial climate conditions simulated by the crop model as the counterfactual has a relative advantage in addressing this concern. Nevertheless, the current method has a notable caveat: that the input type (fertilizer, water, chemical, labor, etc.) that contributes to the projected increase in adaptation cost cannot be differentiated because we associated yield with total production cost when building the production cost and yield curves. Production cost data for each input type are required to overcome this limitation and are worth exploring in future research.

\subsection{Residual damage compared with current climate extremes}

In addition to the comparison with earlier adaptation cost estimates, we compare the residual damage estimated in this study with production losses caused by droughts - one of the most severe climate extremes affecting global agriculture under the current climate (Lesk et al. 2016). Such an exercise helps readers relativize the size of the residual damage.

Globally aggregated drought-induced production losses for the 4 crops from 1983 to 2009 account for $\$ 166$ B (Kim et al. 2019). This value corresponds to an average annual global production loss of \$6 B. However, droughts are naturally variable in climate systems, and if a 1 in 10 recurrence period is assumed for simplicity, then the global drought-induced production loss for an average drought year is $\$ 60 \mathrm{~B}$ (and the production loss is zero for the remaining 9 nondrought years). This means that the projected global decadal mean residual damage at 1.5 and $2{ }^{\circ} \mathrm{C}(\$ 10$ and $\$ 19$ B per year, respectively) would be higher if the average annual global drought-induced production loss is compared, whereas these are lower if the global drought-induced production loss in an average drought year is compared. The global decadal mean residual damage at $3^{\circ} \mathrm{C}(\$ 50 \mathrm{~B}$ per year) would be close to the current global production loss in an average drought year. Note, however, that climate change will occur for coming decades until zero or negative emissions are achieved. The cumulative residual damage for a decade $\left(\$ 100 \mathrm{~B}\right.$ for $1.5^{\circ} \mathrm{C}, \$ 190 \mathrm{~B}$ for $2^{\circ} \mathrm{C}$ and $\$ 500 \mathrm{~B}$ for $3^{\circ} \mathrm{C}$ ) is much larger than the cumulative global drought-induced production loss for the same time interval (\$60 B). These findings highlight that climate change represents a sizable threat to global crop production, even compared with the most severe current climate extremes.

\subsection{Uncertainties}

There are many factors not considered here that could affect the size of the adaptation cost and residual damage estimates. International trade is such a factor, as noted Section 4.2 (Baldos \& Hertel 2015, Hasegawa et al. 2016). The extent of cropland area is projected to increase in the future (Popp et al. 2017, Fujimori et al. 2018), although we maintain it at the current level throughout the study period. Wage and capital returns are not considered, but may decrease adaptation costs once considered. The results presented here are based on a single crop model. A multicrop model ensemble approach (Müller et al. 2017) could be utilized once the simulations of technology-driven yield trends become feasible for global gridded crop models. Such an effort has just begun (ISIMIP 2020).

Increases in the coverage of countries, crop types and use of different assumptions on adaptation may increase adaptation costs. Countries with minimal production levels that are typically developing countries are excluded from this study despite their importance and the need for international adaptation financing. Socioeconomic changes in developing countries in the scenarios used in this study are unprecedently large, and the simulated production cost changes are often numerically unstable and discarded from the analysis. Our estimates represent major cereals and legumes, but cash crops, horticulture, viniculture and livestock products, for which prices are higher than those of cereals, are lacking. Adaptation practices found in the literature include a variety of changes compared with those considered here. We assume that sowing date shift and cultivar switching do not require additional production cost expenditures. However, planning, preparing, facilitating and implementing costs and transaction costs may occur (Panda 2018), even for these agronomic adjustments. Adaptation technology developed at lower warming levels might become outdated once warming progresses, and this scenario might accelerate the obsolescence rate of agricultural knowledge.

\section{CONCLUSIONS}

The present study estimates the adaptation cost for and residual damage to climate change for global crop 
production, with a description of the uncertainty. Our estimates are directly relevant to recent global temperature targets, which are set relative to preindustrial levels. The adaptation considered here is an individual producer's incremental approach. Adaptation costs of this kind have rarely been estimated to date. For the first time, to the best of our knowledge, our assessment presents the adaptation cost for global crop production. The results reveal that the global adaptation cost for the major crops considered in this study will be \$53-78 B per year, depending on warming levels. Once the expenditures on adaptation become difficult for producers to maintain because of the negative impacts of climate change, biological limits of crops or profitability, producers will not be able to bear the adaptation costs, and the global annual residual damage will start to increase from $\$ 10 \mathrm{~B}$ at $+1.5^{\circ} \mathrm{C}$ to $\$ 19 \mathrm{~B}$ at $+2^{\circ} \mathrm{C}$ and to $\$ 50 \mathrm{~B}$ at $+3^{\circ} \mathrm{C}$. The residual damage could exceed the production losses due to current climate extremes, such as droughts. The high level of residual damage indicates that an incremental approach is insufficient to adapt to climate change, and a more transformative approach will be necessary. A further analysis characterizing regional differences in the estimated adaptation cost and residual damage, as well as that comparing the adaptation cost estimates presented here with the funds and investments currently available for adaptation, will benefit policymakers responsible for international adaptation financing and agricultural development.

Acknowledgments. T.I. thanks Shinichiro Fujimori and Tomoko Hasegawa for their comments on an earlier version of this manuscript. Crop model simulations were conducted using the High-Performance Cluster Computing System of the Agriculture, Forestry and Fisheries Research Information Technology Center of the Ministry of Agriculture, Forestry and Fisheries of Japan. We acknowledge the World Climate Research Program's Working Group on Coupled Modeling, which is responsible for the CMIP, and we thank the climate modeling groups (listed in Table S4 in the Supplement) for producing and making their model outputs available. For the CMIP, the US Department of Energy's Program for Climate Model Diagnosis and Intercomparison coordinated and led the development of the software infrastructure in partnership with the Global Organization for Earth System Science Portals. This study utilized the d4PDF database, which was produced under the SOUSEI program sponsored by the Ministry of Education, Culture, Sports, Science and Technology of Japan. T.I., Z.S., W.K. and M.N. were supported by the Environment Research and Technology Development Fund (S-14 and 2-2005) of the Environmental Restoration and Conservation Agency, Japan. T.I., J.F., T.K. and G.F. were supported by Grant-in-Aid for Scientific Research B $(18 \mathrm{H} 02317)$ of the Japan Society for the Promotion of Science.

\section{LITERATURE CITED}

Aguiar A, Narayanan B, McDougall R (2016) An overview of the GTAP 9 data base. J Glob Econ Anal 1:181-208

Baldos ULC, Hertel TW (2015) The role of international trade in managing food security risks from climate change. Food Secur 7:275-290

Beintema N, Stads GJ, Fuglie K, Heisey P (2012) ASTI global assessment of agricultural R\&D spending: developing countries accelerate investment. International Food Policy Research Institute, Washington, DC

* Brown PR, Afroz S, Chialue L, Chiranjeevi T and others (2019) Constraints to the capacity of smallholder farming households to adapt to climate change in South and Southeast Asia. Clim Dev 11:383-400

Chambers JM, Hastie TJ (eds) (1991) Statistical models in S. Chapman \& Hall/CRC, Boca Raton, FL

Chambwera M, Heal G, Dubeux C, Hallegatte S and others (2014) Economics of adaptation. In: Field CB, Barros VR, Dokken DJ, Mach KJ and others (eds) Climate change 2014: impacts, adaptation, and vulnerability. A. Global and sectoral aspects. Contribution of Working Group II to the Fifth Assessment Report of the Intergovernmental Panel on Climate Change. Cambridge University Press, Cambridge, p 945-977

Cramer W, Yohe GW, Auffhammer M, Huggel C and others (2014) Detection and attribution of observed impacts. In: Field CB, Barros VR, Dokken DJ, Mach KJ and others (eds) Climate change 2014: impacts, adaptation, and vulnerability. A. Global and sectoral aspects. Contribution of Working Group II to the Fifth Assessment Report of the Intergovernmental Panel on Climate Change. Cambridge University Press, Cambridge, p 979-1037

*Delcour I, Spanoghe P, Uyttendaele M (2015) Literature review: impact of climate change on pesticide use. Food Res Int 68:7-15

Fuglie K (2018) R\&D capital, R\&D spillovers, and productivity growth in world agriculture. Appl Econ Perspect Policy 40:421-444

F Fujimori S, Iizumi T, Hasegawa T, Takakura J, Takahashi K, Hijioka Y (2018) Macroeconomic impacts of climate change driven by changes in crop yields. Sustainability 10:3673

Gelman A, Rubin DB (1992) Inference from iterative simulation using multiple sequences. Stat Sci 7:457-511

Griliches Z, Mairesse J (1984) Productivity and R\&D at the firm level. In: Griliches Z (ed) R\&D, patents, and productivity. University of Chicago Press, Chicago, IL, p 339-374

*Hasegawa T, Fujimori S, Takahashi K, Yokohata T, Masui T (2016) Economic implications of climate change impacts on human health through undernourishment. Clim Change 136:189-202

Hastings WK (1970) Monte Carlo sampling methods using Markov chains and their applications. Biometrika 57: 97-109

*Hawkins E, Sutton R (2009) The potential to narrow uncertainty in regional climate predictions. Bull Am Meteorol Soc 90:1095-1108

Herdt RW, Capule C (1983) Adoption, spread, and production impact of modern rice varieties in Asia. International Rice Research Institute, Los Baños

* Hoegh-Guldberg O, Jacob D, Taylor M, Bindi M and others (2018) Impacts of $1.5^{\circ} \mathrm{C}$ global warming on natural and human systems. In: Masson-Delmotte V, Zhai P, Pörtner $\mathrm{HO}$, Roberts D and others (eds) Global warming of $1.5^{\circ} \mathrm{C}$. An IPCC special report on the impacts of global warming 
of $1.5^{\circ} \mathrm{C}$ above pre-industrial levels and related global greenhouse gas emission pathways, in the context of strengthening the global response to the threat of climate change, sustainable development, and efforts to eradicate poverty. p3SM-1-3SM-131. https://www.ipcc.ch/site/assets/ uploads/sites/2/2019/09/SR15_3SM_Low_Res.pdf

Iizumi T (2019) Emerging adaptation to climate change in agriculture. In: Iizumi T, Hirata R, Matsuda R (eds) Adaptation to climate change in agriculture: research and practices. Springer Nature, Singapore, p 3-16

Iizumi T, Yokozawa M, Nishimori M (2009) Parameter estimation and uncertainty analysis of a large-scale crop model for paddy rice: application of a Bayesian approach. Agric Meteorol 149:333-348

Iizumi T, Furuya J, Shen Z, Kim W and others (2017a) Responses of crop yield growth to global temperature and socioeconomic changes. Sci Rep 7:7800

Fizumi T, Takikawa H, Hirabayashi Y, Hanasaki N, Nishimori M (2017b) Contributions of different bias-correction methods and reference meteorological forcing data sets to uncertainty in projected temperature and precipitation extremes. J Geophys Res Atmos 122:7800-7819

Iizumi T, Shiogama H, Imada Y, Hanasaki N, Takikawa H, Nishimori M (2018) Crop production losses associated with anthropogenic climate change for 1981-2010 compared with preindustrial levels. Int J Climatol 38:5405-5417

* Imada Y, Maeda S, Watanabe M, Shiogama H, Mizuta R, Ishii M, Kimoto M (2017) Recent enhanced seasonal temperature contrast in Japan from large ensemble highresolution climate simulations. Atmosphere 8:57

IPCC (2018) Summary for policymakers. In: Masson-Delmotte V, Zhai P, Pörtner HO, Roberts D et al. (eds) Global warming of $1.5^{\circ} \mathrm{C}$. An IPCC Special Report on the impacts of global warming of $1.5^{\circ} \mathrm{C}$ above pre-industrial levels and related global greenhouse gas emission pathways, in the context of strengthening the global response to the threat of climate change, sustainable development, and efforts to eradicate poverty. World Meteorological Organization, Geneva

ISIMIP (Inter-Sectoral Impact Model Intercomparison Project) (2020) ISIMIP3b simulation protocol-agriculture. https://protocol.isimip.org/protocol/ISIMIP3b/agriculture.html (accessed 18 Mar 2020)

Ito $J$ (1992) Assessing the returns of R\&D expenditures on postwar Japanese agricultural production. Econ Rev 43: 237-247

Jones HG (2013) Plants and microclimate: a quantitative approach to environmental plant physiology. Cambridge University Press, Cambridge

Kabir MJ, Alauddin M, Crimp S (2017) Farm-level adaptation to climate change in western Bangladesh: an analysis of adaptation dynamics, profitability and risks. Land Use Policy 64:212-224

Kim W, Iizumi T, Nishimori M (2019) Global patterns of crop production losses associated with droughts from 1983 to 2009. J Appl Meteorol Climatol 58:1233-1244

Lesk C, Rowhani P, Ramankutty N (2016) Influence of extreme weather disasters on global crop production. Nature 529:84-87

* Lobell DB, Burke MB (2010) On the use of statistical models to predict crop yield responses to climate change. Agric Meteorol 150:1443-1452

Lobell DB, Gourdji SM (2012) The influence of climate change on global crop productivity. Plant Physiol 160: 1686-1697
Marshall NA, Dowd A, Fleming A, Gambley C and others (2014) Transformational capacity in Australian peanut farmers for better climate adaptation. Agron Sustain Dev 34:583-591

Metropolis N, Rosenbluth AW, Rosenbluth MN, Teller AH, Teller E (1953) Equation of state calculations by fast computing machines. J Chem Phys 21:1087-1092

Mizuta R, Yoshimura H, Murakami H, Matsueda M and others (2012) Climate simulations using MRI-AGCM3.2 with 20-km grid. J Meteorol Soc Jpn 90A:233-258

Mizuta R, Murata A, Ishii M, Shiogama H and others (2017) Over 5000 years of ensemble future climate simulations by $60 \mathrm{~km}$ global and $20 \mathrm{~km}$ regional atmospheric models. Bull Am Meteorol Soc 98:1383-1398

Moore FC, Lobell DB (2015) The fingerprint of climate trends on European crop yields. Proc Natl Acad Sci USA 112:2670-2675

*Müller C, Elliott J, Chryssanthacopoulos J, Deryng D, Folberth C, Pugh TAM, Schmid E (2015) Implications of climate mitigation for future agricultural production. Environ Res Lett 10:125004

* Müller C, Elliott J, Chryssanthacopoulos J, Arneth A and others (2017) Global gridded crop model evaluation: benchmarking, skills, deficiencies and implications. Geosci Model Dev 10:1403-1422

Nelson GC, Valin H, Sands RD, Havlík P and others (2014) Climate change effects on agriculture: economic responses to biophysical shocks. Proc Natl Acad Sci USA 111:3274-3279

* O'Neill BC, Kriegler E, Riahi K, Ebi KL and others (2014) A new scenario framework for climate change research: the concept of shared socioeconomic pathways. Clim Change 122:387-400

Oxfam (2007) Adapting to climate change: what's needed in poor countries, and who should pay. Oxfam Briefing Paper No. 104, Oxfam International Secretariat, Oxford, p 47

*Panda A (2018) Transformational adaptation of agricultural systems to climate change. Wiley Interdiscip Rev Clim Change 9:e520

Popp A, Calvin K, Fujimori S, Havlik P and others (2017) Land-use futures in the shared socio-economic pathways. Glob Environ Change 42:331-345

Porter JR, Xie L, Challinor AJ, Cochrane K and others (2014) Food security and food production systems. In: Field CB, Barros VR, Dokken DJ, Mach KJ and others (eds) Climate change 2014: impacts, adaptation, and vulnerability. A. Global and sectoral aspects. Contribution of Working Group II to the Fifth Assessment Report of the Intergovernmental Panel on Climate Change. Cambridge University Press, Cambridge, p 485-533

Portmann FT, Siebert S, Döll P (2010) MIRCA2000—global monthly irrigated and rainfed crop areas around the year 2000: a new high-resolution data set for agricultural and hydrological modeling. Glob Biogeochem Cycles 24: GB1011

R Development Core Team (2014) R: a language and environment for statistical computing. R Foundation for Statistical Computing, Vienna

* Ray DK, West PC, Clark M, Gerber JS, Prishchepov AV, Chatterjee S (2019) Climate change has likely already affected global food production. PLOS ONE 14:e0217148

Rosas F (2011) World fertilizer model—the WorldNPK model. CARD Working Paper. 545. https://lib.dr.iastate.edu/card_ workingpapers/545 
Schleussner CF, Lissner TK, Fischer EM, Wohland J and others (2016) Differential climate impacts for policy-relevant limits to global warming: the case of $1.5^{\circ} \mathrm{C}$ and $2{ }^{\circ} \mathrm{C}$. Earth Syst Dynam 7:327-351

Shiogama H, Imada Y, Mori M, Mizuta R and others (2016) Attributing historical changes in probabilities of recordbreaking daily temperature and precipitation extreme events. Sci Online Lett Atmos 12:225-231

* Siebert S, Kummu M, Porkka M, Döll P, Ramankutty N, Scanlon BR (2015) A global data set of the extent of irrigated land from 1900 to 2005. Hydrol Earth Syst Sci 19: 1521-1545

Stern N (2007) The economics of climate change: the Stern review. Cambridge University Press, Cambridge

Sultan B, Defrance D, Iizumi T (2019) Evidence of crop production losses in West Africa due to historical global warming in 2 crop models. Sci Rep 9:12834

Takakura J, Fujimori S, Hanasaki N, Hasegawa T and others (2019) Dependence of economic impacts of climate change on anthropogenically directed pathways. Nat Clim Chang 9:737-741

UNDP (United Nations Development Programme) (2007) Human development report 2007/2008. Fighting climate change: human solidarity in a divided world. Palgrave McMillan, New York, NY

UNEP (United Nations Environment Programme) (2016) The adaptation finance gap report 2016. UNEP, Nairobi

UNFCCC (United Nations Framework Convention on Climate Change) (2007) Investment and financial flows to address climate change. UNFCCC, Bonn

UNFCCC (2018) The Paris agreement. https://unfccc.int/ process-and-meetings/the-paris-agreement/the-parisagreement (accessed 28 Oct 2019)

Valdivia RO, Antle JM, Rosenzweig C, Ruane AC and others (2015) Representative agricultural pathways and scenarios for regional integrated assessment of climate change impacts, vulnerability, and adaptation. In: Rosenzweig C, Hillel D (eds) Handbook of climate change and agroecosystems. Imperial College Press, London, p 101-145

* van Vuuren DP, Edmonds J, Kainuma M, Riahi K and others (2011) The representative concentration pathways: an overview. Clim Change 109:5-31

van Vuuren DP, Kriegler E, O'Neill BC, Ebi KL and others (2014) A new scenario framework for climate change research: scenario matrix architecture. Clim Change 122: 373-386

*Vermeulen SJ, Challinor AJ, Thornton PK, Campbell BM and others (2013) Addressing uncertainty in adaptation planning for agriculture. Proc Natl Acad Sci USA 110: 8357-8362

Wiebe K, Lotze-Campen H, Sands R, Tabeau A and others (2015) Climate change impacts on agriculture in 2050 under a range of plausible socioeconomic and emissions scenarios. Environ Res Lett 10:085010

* World Bank (2007) Investment framework for clean energy and development. World Bank, Washington, DC. http:// documents.worldbank.org/curated/en/338911468157194334/ An-investment-framework-for-clean-energy-anddevelopment-an-investment-framework-clean-energyand-development

World Bank (2010) Economics of adaptation to climate change: synthesis report. World Bank, Washington, DC

Wreford A, Renwick A (2012) Estimating the costs of climate change adaptation in the agricultural sector. Perspect Agric Vet Sci Nutr Nat Resour 7:1-10

Zhou L, Turvey CG (2014) Climate change, adaptation and China's grain production. China Econ Rev 28:72-89

* Zhu P, Jin Z, Zhuang Q, Ciais P and others (2018) The important but weakening maize yield benefit of grain filling prolongation in the US Midwest. Glob Change Biol 24: 4718-4730

\section{APPENDIX.}

\section{PRODUCTION COST MODEL CALIBRATION}

In the calibration of the production cost model, it was straightforward to apply the least-squares method to the log-transformed form of Eq. (1):

$$
\log \left(\frac{Y}{I}\right)=\log (A)+\alpha \log (C)+\beta \log (R)
$$

This equation provides a set of regression coefficients $(A$, $\alpha$ and $\beta$ ) that produce an excellent fit between the reported and reproduced yields (Fig. S4a). However, these coefficient values do not accurately reproduce the reported production costs when the reported yields and knowledge stocks are input to Eq. (5) (Fig. S4b).

This difference is probably because the conditions under which the coefficient values need to be satisfied are different between Eq. (A1) and Eq. (5). In the former equation, the assumption that $A, \alpha$ and $\beta$ are independent of each other is used. However, the latter equation requires satisfying the following expressions:

$$
A<\frac{Y}{I R^{\beta}} \text { and } \beta<\frac{\log \left(\frac{Y}{I A}\right)}{\log (R)}
$$

which are derived by the preconditions of $C>0$ and $\alpha>0$ and indicate that $A$ and $\beta$ are dependent on each other ( $\alpha$ is independent of $A$ and $\beta$ ). For these different assumptions used in the calibration, the optimized values of the coefficients are expected to disagree with each other.

Therefore, we apply the MCMC method to calibrate Eq. (5) but not Eq. (A1). MCMC is powerful in calibrating a nonlinear model and is applicable even when the coefficient values in a model are correlated with each other. These advantages are necessary when calibrating Eq. (5), which has interactions between the coefficient values (Eq. A2). The coefficient values with the largest likelihood reproduce the reported production costs well in exchange for the relatively lower correspondence between the reported and reproduced yields (Fig. S4c,d). The nonlinear least-squares method available through the nls function with the port option in $\mathrm{R}$ ( $\mathrm{R}$ Development Core Team 2014) also successfully determines the coefficient values, as did the MCMC method, as long as the ranges of the coefficient values are appropriately set (Fig. S4e,f). However, a number of trials and errors are required for the nonlinear least squares method to seek an appropriate range of coefficient values from the possible candidates. For this reason, we utilize the MCMC method for the production cost model calibration. 